\title{
Social Media to Promote Content Learning, Motivation, and Collaboration in Teaching Research
}

\author{
Aurelio P. Vilbar \\ University of the Philippines Cebu \\ College of Social Sciences \\ Cebu City, Philippines \\ apvilbar1@up.edu.ph
}

\begin{abstract}
Despite the importance of offering Research courses in the curriculum, there is a dearth of research on how to teach Research methods or courses. This study presents the attitudes and perceptions of the students towards using Facebook (FB) Group in teaching Research. It was conducted for one semester to 75 secondary students at the University of the Philippines High School Cebu, Cebu City, Philippines. Employing descriptive research, this study used the Student Attitudes and Perceptions of Using FB Survey by Pollara \& Zhu (2011) which was validated through focus group discussion. Findings show that students "Somewhat agree" that using FB Group in teaching Research developed their content learning, motivation to learn and collaborative skills to achieve research tasks. The instant messaging promotes collaborative learning and direct interaction among co-students and teachers. Despite the distractions in the FB Group environment and the lack of internet connection among the students' homes, the respondents still suggested to continue using FB Groups as an alternative elearning system. They further suggested that teachers must monitor their students' behaviors when using FB during class hours. This study further suggested on conducting a correlation on the impact of using FB Groups on the students' academic performance.
\end{abstract}

Keywords-Social media in teaching; Facebook as elearning system; teaching research methods

\section{INTRODUCTION}

Research courses can develop critical thinking expertise, effective analytical, research, and communication skills that can empower students to be globally-competitive. Research is essential to economic and social development of the globalized society [1]. According the Philippines' new K to 12 Curriculum, Offering Research supports a curriculum that promotes an education that is research-based, contextualized and global whose pedagogical approaches are constructivist, collaborative, and inquiry-based [2].

Despite these benefits, there are limited studies on teaching Research. Studies show that Research is a complex domain involving a combination of procedures and definitions, many of which the academics have no uniform concepts. It is also considered to be a dry, uninteresting and complicated subject which produced high levels of anxiety [3] To make Research teaching less anxious and more learnercentered, studies show that using elearning system is effective in discussing research methods and statistics [4].

Facebook, the most popular social network, with more than 1.8 billion active users [5] has potentials to be an elearning system in teaching Research among adolescents. Facebook is a useful tool to deliver materials, support learning, and develop learning motivation [6], can promote active learning, collaboration and peer communications [7] [8]. With proper planning in the curriculum, FB can be a useful teaching-learning space [9]. In the context of Research whose outputs are written academic papers, using FB can promote positive attitude about learning the content [10].

However, many teachers claimed that social networking sites may disengage students from learning traditional skills and literacies [11]. In addition, some students generally perceived FB as a social media technology rather than a formal teaching-learning environment [12]. As a social media, FB can cause distractions which can disengage the students from their academic focus [13] [14]. In addition, most published research focused on social networking sites in general and not on the impact on students' performance, especially on secondary level. [15].

This study therefore aims to determine the attitudes and perceptions of secondary students of using Facebook Group in teaching Research. Cognizant of the adolescents' enthusiasm on technological advances [16] and the educational potentials of using FB Group, this study aims to use Facebook group as an elearning system in teaching-learning Research in secondary level. As a learning management system in this study, the FB group became the online platform for secondary students to read, post, download, upload, and share researchrelated files and to do collaborative discussion. This research had the following questions:

1. What are the attitudes and perceptions of the students in using FB group in teaching Research?

This research is supported by the University of the

Philippines Cebu Faculty Research Grant 2016. 
2. What are the challenges in using FB group in teaching Research?

\section{LiterATURE REVIEW}

\section{A. Challenges in Teaching Research}

On her investigation on best practice in teaching Research, Groessler concluded that the lack of pedagogic culture in teaching research methods is one major challenge in its discipline. Teachers handling Research may have research expertise but may not have pedagogical background and receive little guidance on teaching. There is a dearth of Teaching Research curriculum evaluation that assesses the what and the how students learn in the course. From the learners, there is anxiety towards quantitative methods, failure to see the relevance of the course to their lives, and lack of motivation to learn the content. [17].

Another challenge is the absence of context in conducting the research which made the lessons less engaging. Research methods have lecture-based delivery which can be too difficult for the students to fully grasp and put into practice, hence an activity-based approach to learning Research was recommended [18].

Using project-based learning with close supervision of student group and planning can make Research courses more engaging. Research teachers should integrate these educational principles to promote student success: Learning by doing, hands-on practice, and active learning techniques [19].

In addition, using an activity-based learning approach to teaching Research can empower student participation and make learning and teaching more practical, enjoyable, and applicable to real-life situation [20].

\section{B. Impact of Using Facebook in Teaching}

Using Facebook shows a positive correlation between the students' academic performance and the frequency of use of FB for educational purposes. The students perceived FB to be a learning aid [21]. FB's social activities enhance the students' ability to be connected with their learning environment which can be used as a communication platform to students with low self-esteem [22].

Students who never viewed the FB postings reported to have lower engagement and understanding of the class discussion and lower appreciation of the link between the FB content and the lecture material. Successful integration of FB in the course requires timing of content delivery and the students' own perspectives on using social media for academic purposes [23].

In an English class which used FB group, results showed that students achieved better performance in the second small group discussion test and there were positive correlations between students' final score and number of postings. Students had high level of satisfaction with their discussion activities in FB [24].

As a blended learning tool in teaching high school precalculus, FB was used as an extension of the traditional classroom instruction. Findings showed that students had positive perceptions on the educational value of FB and further suggested on supplementing traditional teaching with the FB group to promote a more effective teaching [25]. In addition, the educational capabilities of FB have a positive impact on students' perceptions on the ease of use of social networking sites. [26].

FB is a useful tool to deliver course materials and support learning. Most respondents felt motivated and enjoyed accomplishing their tasks [27]. However, the students' excitement in the FB environment may lead to attention distraction, if not well-guided. Chatting on FB can promote collaborative learning, but it can also be a source of distraction for some students cannot handle multitasking tasks which may have a negative impact on them due to cognitive overload [28].

\section{MeThOdOLOGY}

\section{A. The Participants}

The respondents were limited to the 75 Grades 8 and 9 students of Research Class at the University of the Philippines High School (UPHS), Cebu City, Philippines. UPHS is the laboratory high school of the University of the Philippines Cebu Master of Education Program where faculty and researchers conduct studies regularly on or with the high school students on topics related to education, pedagogy, and materials development. Hence, for research ethics, all parents and children received orientation about the nature of the school. The respondents' ages range from 13-15 years old when the study was conducted. The study was conducted for one semester from January 2017-June 2017.

Research is a core course of the Junior High School which is taught for two hours per week from Grades 7 to 10 . The course objective of Research 8 was to conduct data gathering through a survey and interview and present findings in a table/chart while Research 9 aimed to conduct a quantitative research, use statistical analysis and present findings.

Each grade had a Facebook Group where students and students did the following: uploading, downloading, sharing, and posting of files; giving comments to the posts. The posts and files can be academic paper, research, photos, film clips, related to the course or the class activities. Figures 1 to 4 are screen shots of the sample activities in the Research Classes. 


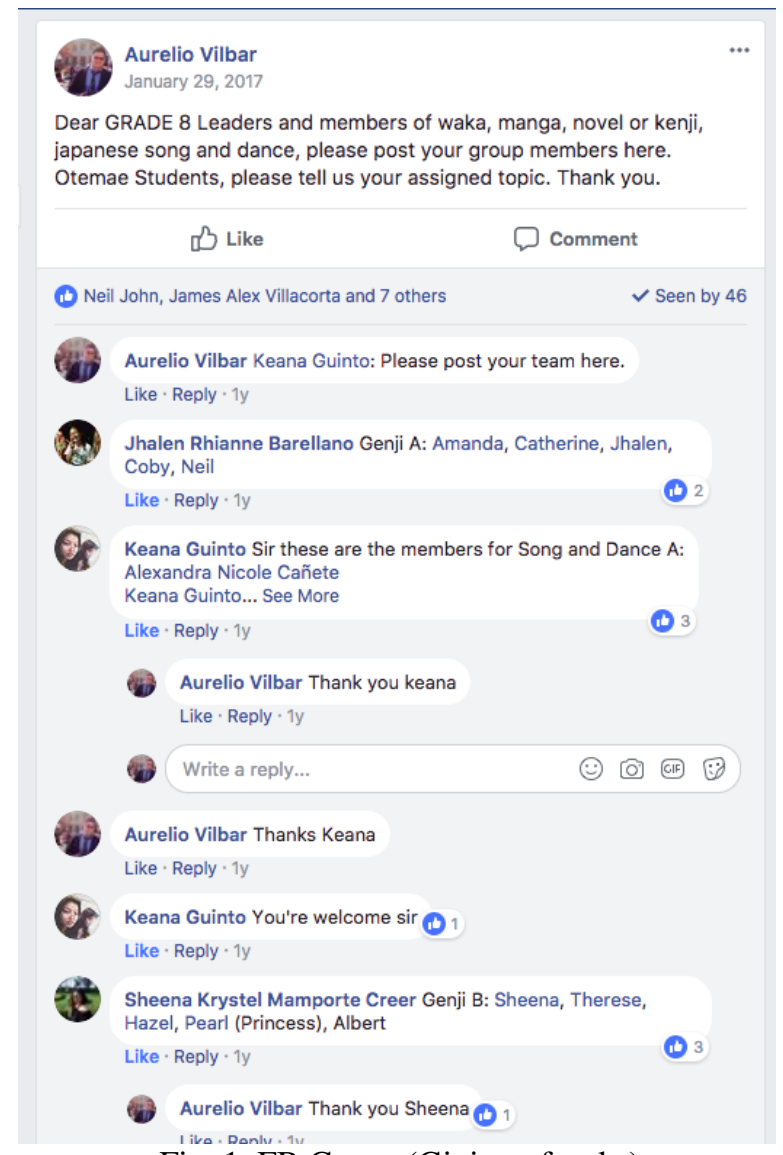

Fig. 1. FB Group (Giving of tasks)

Figure 1 shows the screen of Grade 8's FB Group in which the teacher gave his tasks to the students to post their group members and names on their group and the reply of the leaders.

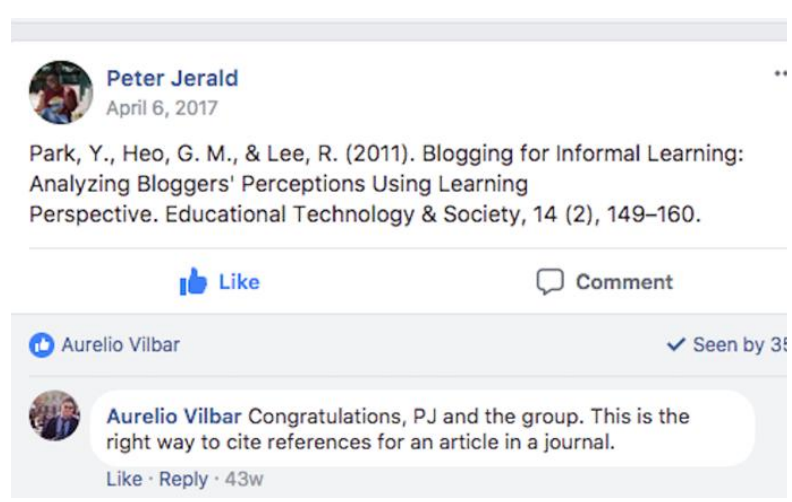

Fig. 2. FB Group (Activity on APA Citation Format)

Figure 2 shows the answer of Peter Jerald on the activity "Using APA format in citing references".

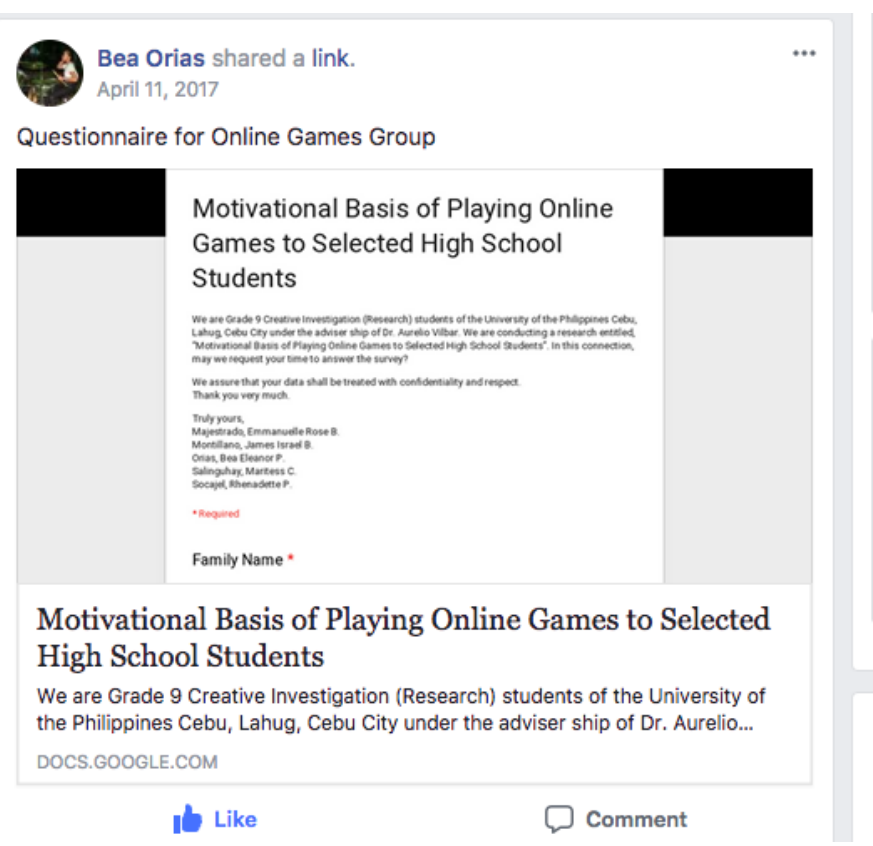

Fig. 3. FB Group (Answering of Online Questionnaire)

Figure 3 shows the screen shot of Bea's request for her classmates to answer the questionnaire on playing online games.

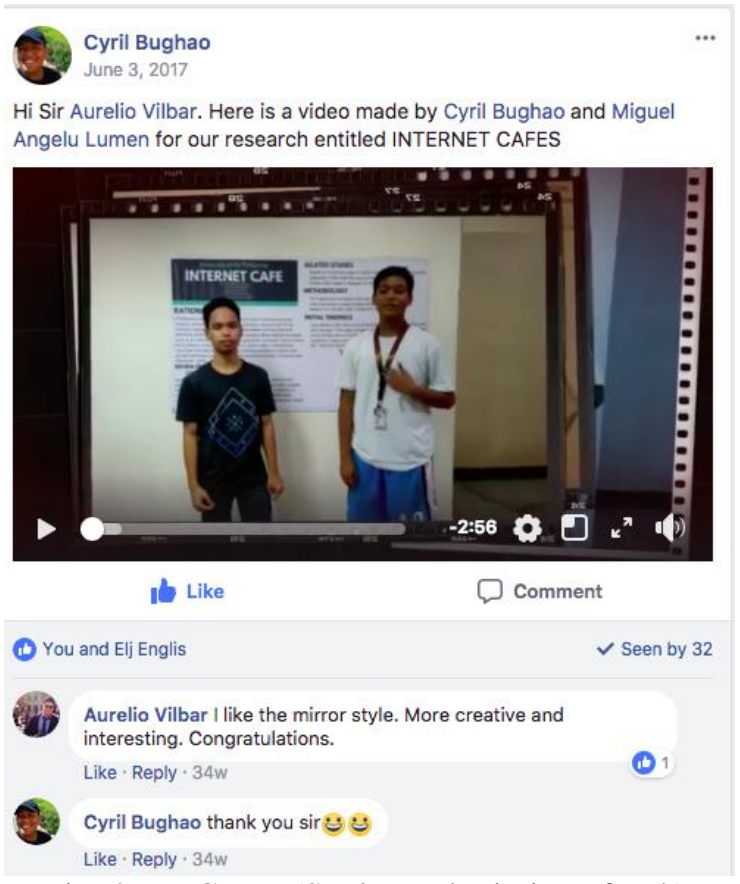

Fig. 4. FB Group (Student submission of task)

Figure 4 shows the video of Cyril and Miguel presenting their research on the use of internet cafes in selected areas. 


\section{B. Data Collection and Analysis}

To determine the attitudes and perceptions of using FB in teaching-learning Research, the Student Attitudes and Perceptions Survey by Pollara \& Zhu [6] was used. The 34item survey addressed the constructs of Pedagogy, Motivation, Interaction with Students, Interaction with the Teacher, and Technology. Attitudes and perceptions were measured on a 7point Likert scale. The reliability of the original instrument was .97 which is considered "Good". A revision to the Pollara and Zhu questionnaire were open-ended questions to the students about the challenges of using FB in class and their suggestions to their classmates and to the teachers.

The respondents' answers were analyzed using descriptive statistics. A content analysis of the postings and semistructured interviews were conducted to determine the respondents' experiences on using the FB group were conducted and were validated through focus group discussions.

\section{FINDINGS AND DiscuSSION}

As shown in Figure 1, the overall attitudes and perceptions of the students in using FB Group in teaching Research is 4.94 (Somewhat agree). This implies that the secondary students fairly believe that the technological features of FB Group can promote learning concepts on their research, develop motivation in achieving their research tasks, and foster interaction among other students and teachers in the conduct of their research.

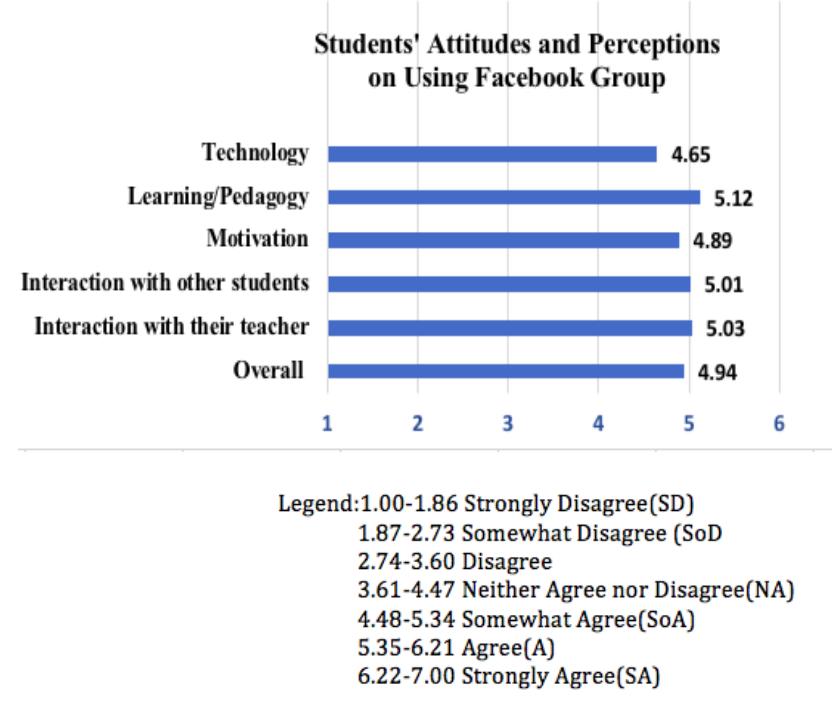

Fig. 5. Student's Attitudes and Perceptions on Using Facebook Group

\section{Learning/Pedagogy}

With a mean of 5.12 (Somewhat agree), Learning/Pedagogy received the highest among the five constructs. When asked how did they learn in the FB group during the focus group discussion (FGD), the students claimed that in the FB Comments Section, they could give comments or critiques to someone's post and could even discuss things for others to see. Student A added, "We can discuss on how to search for related literature and others can see the discussion thread. Others can just view them at some time. We no longer keep on repeating the information."

Student B stressed, "When I asked for the topics from my classmates, they could easily share the soft copy handouts and I could learn from the shared files."

This benefit of using FB group validates the principle that using active learning techniques in teaching the so-called dry subject Research can empower students to do independent learning [18]. Their learning task of summarizing the Review of Related Literature and posting the files in the FB Discussion Board supported the activity-based learning approach in which students experienced real academic tasks of analyzing theories and studies; and then drawing a schematic diagram [17] [18].

This whole socio-cognitive engagement demonstrates the essence of Constructivism in education. The students use a variety of internal developmental processes that they are able to operate in their Research class in cooperation with their peers and the FB Group environment. These authentic processes may include the immediate feedback from the classmates and teacher, the internet browsing for further information, and the file storage for referencing; and once these processes are internalized, they become part of the students' independent developmental achievement [29].

Therefore using FB Group under the framework of Constructivism can promote collaborative learning and can assist the academic performance of the students [24] [27] [29].

What added to the novelty is the immediate comments they receive from their classmates and teacher when they post ideas or files. This instant communication may not be feasible in the traditional classroom, thus making the whole new elearning experience enjoyable [7] [8] [9]. As a blended learning tool in teaching Research, the FB Group becomes a supplementary elearning space for the traditional classroom [20].

\section{Interaction with other students and teacher}

The students somewhat agree that the FB Group fairly developed their interactions with other students (5.01) and with the teacher (5.03). In the FGD, the respondents highlighted that the FB Group made communication faster and interaction clearer. As claimed by Student B, "Facebook is designed in a way where people can freely communicate with each other so observing the posts and the discussions made by the students and adviser, communication was an important tool."

The interactions among the students to their classmates or student-respondents from other grades or school prove that FB is an alternative free communication system among the 
students. The FB Group has become a channel of messages related to academics, personal or extra and co-curricular activities because of its user-friendly feature [20] [22] [23]. Considering that these secondary students are digital natives with enthusiasm on technological advances [16], using FB in learning is part of their socio-cognitive nature.

Another effective tool in FB is the chat feature. It has become an alternative direct communication platform to the introvert students to directly ask their teachers with lesser anxiety compared to the traditional face-to-face teaching [22]. From the FGD, students claimed, "We could easily message our teachers for inquiry or verification related to the subject or school activities. Unlike in the face-to-face communication which can promote anxiety among us."

\section{Motivation}

The respondents were somewhat motivated (4.89) to perform and accomplish their Research tasks in the FB environment. They asserted during the FGD that they got motivated when they received notifications from FB that their group mates already uploaded the required file. Student C said, "When a teacher posts comments commending our work, I feel motivated to do more."

Student D added, "I got motivated to our projects uploaded before the deadline and see emojis".

The assertions of Students C and D support studies that students feel motivated posting their accomplished tasks in the FB Group [27]. FB fostered their positive attitude in learning Research content and confidence.

\section{Challenges}

From the open-ended questionnaire, the top two disadvantages of using FB in teaching Research are distractions (36 or $50.704 \%$ ) and no internet access (28 or $39.437 \%$ ). When asked what caused distractions in the FGD, the students elaborated that when they opened the FB Group, they received notifications from their news feed which made them curious to check them and access the websites.

Table 1. Disadvantages of using Facebook Group in Teaching Research

\begin{tabular}{l|ll}
\hline Disadvantages & $\boldsymbol{N}$ & $\mathbf{\%}$ \\
\hline Distractions & 36 & 50.704 \\
No internet access at home & 28 & 39.437 \\
Dependence & 3 & 4.225 \\
Misinformation & 3 & 4.225 \\
No face to face conversation & 1 & 1.408 \\
& 71 & 100.000 \\
\hline
\end{tabular}

Student E added, "When I opened the FB Group to download readings, I also visited other interesting websites and played games and then I just realized that my focus was diverted to the games, not on my readings". Student F asserted, "FB Group can be disadvantageous for us because we got distracted".

The students' reactions validate studies that as social media, FB has limitations to be used as a formal teaching environment because it can distract students and disengage them from their academic focus [28]. The entertainment and social media platform of FB such as videos and games can be more stimulating to the adolescents.

When asked if teachers should stop using FB Group in teaching since students can be distracted, all respondents, however, asserted to continue using FB due to its fun, accessible, collaborative, and less-threatening nature. The stressed that FB Group can promote bonding among students and teachers in which students do not have much anxiety in messaging their professors. They suggested to their costudents that in using FB in Research, they should focus on the academic tasks and collaboration and avoid visiting other distracting websites. They also suggested to their teachers that in using FB during in the classrooms, they must do more interactions with the students and monitoring. Students can be visiting websites not related to the Research tasks.

This is the academic ambiguity of using social media in teaching content courses. The users are both aware of the advantages and disadvantages of using the social media technology on their learning. The students fully understand that they can get distractions while accessing, reading, uploading, and posting academic file but they believe FB is a good learning platform.

Another challenge expressed by the respondents is having no internet access at home which posed problems to students in accessing files, reading announcements and other communications related to the course or school. The findings validate studies that students from developing countries can experience digital divide or lack of access to information due to financial capabilities or infrastructure problems [13] [14]. nce the respondents belong to economically-disadvantaged group, most of them do not have an internet connection at home or personal cellular phones.

Student G said, "I will not be updated with the files shared by my classmates since my family does not have internet connection".

Student H stressed, "I'm only using the free data feature of Facebook which allows me to do free messaging but not viewing of files such as pdf, Microsoft word, or pictures. So if my classmates and teachers uploaded files, I cannot view all of them."

To avoid these problems, the students, in the FGD, suggested that teachers should avoid giving urgent 
announcements or tasks via FB group and uploading large files after class hours since they cannot view, download, and print all of them. Viewing the notifications and downloading denotes that students need to go internet cafes or shops which have cost implications.

\section{CONCLUSION}

The students perceive that using Facebook Group in teaching Research developed their content learning, motivation to learn and collaborative skills to achieve research tasks. As an elearning system, FB group allows students to read, post, comment and share files related to their academic tasks outside of the traditional classroom. These tasks develop their academic reading and writing.

The social media's instant messaging feature promotes collaborative learning due to the direct interactions among their co-students and teachers. Given the nature of Research to be inquiry-based, students freely discuss the research outputs in the chat box with the presence of the teachers in a non-threatening environment compared to an oral recitation in the classroom.

Despite the distractions in the FB Group environment and the lack of internet connection among the students' homes, the respondents still suggested to continue using FB Groups but teachers must limit the number of uploaded files for reading and printing. They further suggested that teachers must monitor their students' behaviors when using FB during class hours.

This study further suggested on conducting a correlation study on the impact of using FB Groups on the students' academic performance.

\section{ACKNOWLEDGMENT}

This research was supported by the University of the Philippines Cebu Faculty Grant 2017 and the Central Visayas Studies Center, UP Cebu. The respondents were the Grades 8 and 9 students at the University of the Philippines in academic year 2016-2017 and the Research Assistant was Joshua Allen Gabayan.

\section{REFERENCES}

[1] U. of Skovde, "The importance of research and its impact on education," Study International, 11-Jan-2017. [Online]. Available: https://www.studyinternational.com/news/theimportance-of-research-and-its-impact-on-education/. [Accessed: 29-Jan-2018].

[2] Official Gazette (2013). Implementing Rules and Regulations of the Enhanced Basic Education Act of 2013. Available on: http://www.gov.ph/

[3] A. J. Onwuegbuzie et al, "Utilizing mixed methods in teaching environments to reduce statistics anxiety," International Journal of Multiple Research Approaches, vol. 4, (1), pp. 28-39,
2010.

Available: https://search.proquest.com/docview/578480990?accountid=472 53.

[4] A. Rock, W. Coventry, M. Morgan and N. Loi, "Teaching Research Methods and Statistics in eLearning Environments: Pedagogy, Practical Examples, and Possible Futures", Frontiers in Psychology, vol. 7, 2016.

[5] R. Hutt, "The world's most popular social networks, mapped," The world's most popular social networks, mapped, 20-Mar-2017. [Online]. Available: https://www.weforum.org/agenda/2017/03/most-popular-socialnetworks-mapped/. [Accessed: 10-Jan-2018].

[6] P. Pollara and J. Zhu, "Society for Information Technology \& Teacher Education International Conference," in Social Networking and Education: Using Facebook as an Edusocial Space, 2011.

[7] Tan, E.X. \& Low, Y.C., "The Perception and Acceptance of Students towards using Social Networking Sites in Teaching and Learning. In Z. Abas et al. (Eds.), Proceedings of Global Learn Asia Pacific 2010. (pp. 247-252). AACE.

[8] I. Fares \& A. Mashaqbeh. "Facebook Applications to Promote Academic Engagement: Student's Attitudes towards the Use of Facebook as a Learning Tool", I.J. Modern Education and Computer Science, 2015, 11, 60-66 . Published Online November 2015 in MECS (http://www.mecs-press.org/) DOI: 10.5815/ijmecs.2015.11.07

[9] I. Guha, "Engaging Students in Learning through Social Networking: users' perspectives," Investigations in University of Teaching and Learning: Vol. 5, no. 2, 96-100, 2009.

[10] M.K. Kabilan, N. Ahmad, M.J.Z., "Facebook:An online environment for learning of English in institutions of higher education? Internet and Higher Education: Vol. 13 Iss. 4 pp. 179-187. doi: 10.1016/j.ihedu.2010.07.003

[11] T. Brabazon, The University of Google Education in the (Post) Information Age. London: Taylor and Francis, 2016.

[12] N. Selwyn, "Faceworking: exploring students education-related use ofFacebook," Learning, Media and Technology, vol. 34, no. 2, pp. 157-174, 2009.

[13] I. Desabille, J. T. Jainar, B. Linaza, M. J. Magdalaga, M. J. Otic, and M. P. Ranili, "The perceptions of students and teacher towards the use of Facebook Group for academic purposes," thesis, 2015.

[14] Pedroso, K. "Using Facebook Group as an Edusocial Space in Teaching Research," thesis, 2016.

[15] M. N. Nurrulrabihan et al, "Design of guidelines on the learning Psychology in the use of Facebook as a medioum for teaching and learning in secondary school," The Turkish Online Journal of Educational Technology, Vol 14 (1), pp., 2015. Available: https://eric.ed.gov/?id=EJ1057337

[16] Eastman, J. K., and Liu, J., (2012), "The impact of generational cohorts on status consumption: an exploratory look at generational cohort and demographics on status consumption", Journal of Consumer Marketing, 29(2): 93-102.

[17] "Teaching Research Methods: An Occasional Paper, http:// itali.uq.edu.au/filething/get/8798/Teaching\%20Research\%20Me thods_150118.pdf. pp. 1-29, Sep-2017

[18] Fallon, Eimear; Walsh, Stephen; and Prendergast, Terry (2013) "An Activity-based Approach to the Learning and Teaching of Research Methods: Measuring Student Engagement and Learning," Irish Journal of Academic Practice: Vol. 2: Iss. 1, Article 2. Available at: h p://arrow.dit.ie/ijap/vol2/iss1/

[19] M-B. Raddon, A. Caleb-Scott, "Integrating the Complete Research Project into a Large Qualitative Data," Teaching Psychology, vol 36, 2., April 2008. Available:

[20] Fallon, Eimear; Walsh, Stephen; and Prendergast, Terry (2013) "An Activity-based Approach to the Learning and Teaching of Research Methods: Measuring Student Engagement and Learning," Irish Journal of Academic Practice: Vol. 2: Iss. 1, Article 2 
[21] Dragan Lambić. 2016. Correlation between Facebook use for educational purposes and academic performance of students. Comput. Hum. Behav. 61, C (August 2016), 313-320. DOI: http://dx.doi.org/10.1016/i.chb.2016.03.052

[22] N. B. Ellison, C. Steinfield, and C. Lampe, The Benefits of Facebook "Friends:" Social Capital and College Students' Use of Online Social Network Sites. Journal of Computer-Mediated Communication, 12, 1143-1168, 2007.

[23] B. Dyson, K. Vickers, J. Turtle, S. Cowan, and A. Tassone, "Evaluating the use of Facebook to increase student engagement and understanding in lecture-based classes," Higher Education, vol. 69, no. 2, pp. 303-313, Jul. 2014.

[24] S. Wichadee and W. Orawiwatnakul, "Cooperative Language Learning: Increasing Opportunities For Learning In Teams," Journal of College Teaching \& Learning (TLC), vol. 9, no. 2, p. 93, 2012.

[25] A. Haygood and P. Hycy Bull, "Let's Face it: Integrating Facebook in Precalculus High School Course", I-managers Journal of Education Technology. Vol. 8, Sec. 4. March 2012

[26] E. Tan \& Y.C.Low, "The Perception and Acceptance of Students towards Learning". In Z. Abas et. al. (Eds.) Proceedings of Global Learn Asia Pacific 2010. (pp. 247-252)

[27] I. F. Al-Mashaqbeh, "Facebook Applications to Promote Academic Engagement: Student's Attitudes towards the Use of Facebook as a Learning Tool," International Journal of Modern Education and Computer Science, vol. 7, no. 11, pp. 60-66, Aug. 2015.

[28] R. Junco \& S. Cotten, "The relationship between multitasking and academic performance". In Computers \& Education, Vol. 59, Iss. 2, 505-514, 2012.

[29] L. Vygotsky, (1978). Mind in Society: the Development of Higher Psychological Processes. Cambridge, MA: Harvard University Press 